\title{
Excellence in Innovation and Knowledge Economy
}

\author{
Yücel Altunbaşak
}

\section{Introduction}

This chapter addresses the challenge for middle-income and technologically developing countries to reach sustainable high levels of welfare based on $R \& D$, innovation, and education. The initial discussion focuses on the middle-income trap, and subsequently proceeds to the discussion of the key components of an R\&D, innovation, and entrepreneurship system intended to overcome this trap. The key components are built upon four categories of best practices. The first two categories are best practices to foster entrepreneurship (techno-entrepreneurship, venture, entrepreneurship culture) and mission-oriented programs, including mega projects. The third and fourth categories are stimulating research quality (performance-based funding schemes) and supporting the innovation system with $R \& D$ awareness. The best practices are drawn from leading examples of policy mechanisms from the Republic of Turkey, the US, South Korea, Japan, Brazil, India, China, Singapore, Mexico, and EU countries (UK, Sweden, Finland, and the Czech Republic). The chapter concludes with policy advice and key recommendations to improve innovation excellence in technologically developing countries, including implications for oil-rich countries.

\section{R\&D and Innovation to Overcome the Middle-Income Trap}

The fast pace of technological developments in our age imposes a challenge to middle-income and less technologically developed, high-income countries to strive to reach the highest peak in $R \& D$ and innovation. This challenge is none

Y. Altunbaşak ( $\square)$

Scientific and Technological Council of Turkey (TUBITAK), Ankara, Turkey

e-mail: yucel.altunbasak@gmail.com 
other than the ambitious process of seeking to ascend an apex of excellence in a pursuit of 'excellence in innovation.' On this path, countries may be faced with barriers that may hinder them from making full use of their potential in order to rise toward the peak. Most notably, these barriers may be associated with the state of the innovation system and its integrity when compared to the progress of economic growth. In such a situation, countries must surmount another hurdle, this time to rise up to the challenge of transforming their economy into one that is based on knowledge and innovation. In a technical sense, countries must overcome the situation of what is known as the "middle-income trap" to reach the status of a knowledge-based economy in a relatively short period of time.

The concept of the 'middle-income trap' defines a condition in which middleincome countries are restricted in their ability to increase gross national income (GNI) per capita despite their efforts to do so. A similar situation applies to technologically less advanced, high-income countries, such as the Kingdom of Saudi Arabia (KSA), which need to develop ascending strategies other than the exploitation of natural resources. In this condition, the income of a country increases sufficiently to enable it to advance beyond low-skilled labor-intensive activities. Yet, since the innovation system, including its physical and human capital, has not been developed sufficiently, the quality of the outputs of the country remains underdeveloped. This limits the country's capability to compete with high-income countries in highly sophisticated products. The country continues to remain behind advanced economies in higher-value products, that in turn affects their relative standing in GNI per capita values [1,2].

Figure 1 compares countries based on the level of their progress in GNI per capita values over a 50-year timeframe. The axes are based on GNI per capita in 1963 and 2013, respectively. In Fig. 1, those countries that sustained their growth are positioned in the top-right corner, while those that escaped the middle income trap and experienced a quantum leap in GNI per capita values are grouped top center. The countries that remained in the middle-income trap are situated in the boxed area in the center of Fig. 1 (see red box), while those countries that become poorer are located in the bottom half. The axes are the logarithm of the ratio of GNI per capita values relative to the US values in 1963.

\subsection{Comparative Perspectives for the Middle-Income Trap}

Numerically, the threshold for escaping the middle-income trap and graduating to the high-income status is defined as requiring a GNI per capita of $\$ 12,746$ at 2011 prices [3]. The number of economies that made this transition is limited [4]. Only about one quarter of the current OECD member countries succeeded in doing so [5]. The middle-income trap is also persistent in emerging economies since economic growth tends to slow down once the lower hanging fruits of technology transfer are harvested. In contrast, those countries that succeeded in making the transition have one important feature in common: they have excelled in developing advanced, indigenous technologies and in investing in education. 


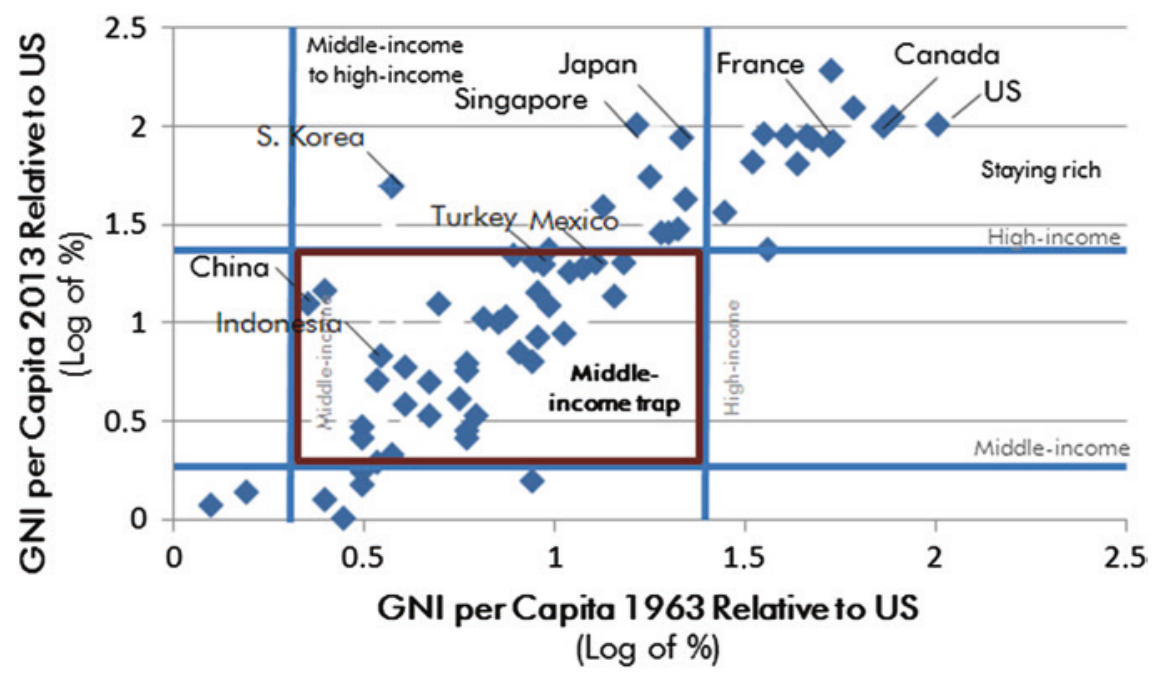

Fig. 1 Depiction of the relative standing of countries over a 50-year timeframe (redrawn for current years based on World Bank dataset [3]. Original graph is provided for 1960 and 2008 in Ref. [4] )

Based on relative GNI per capita values over the course of 50 years, Fig. 1 indicates that countries such as the US, Canada, and France have sustained their economic growth. South Korea, Japan, and Ireland have overcome the middle-income trap and are now their challengers. The next group of countries is the group that remains in the middle-income trap. China, Indonesia, Mexico, and Turkey are examples of countries in this area, although this does not necessarily signify lack of progress. Based on the Global Competitiveness Report [6], both Mexico and Turkey are indicated as countries in 'transition' to innovation-based economies. In contrast, some of the oil-rich countries, such as Saudi Arabia, will be placed above the middle-income trap. The GNI per capita of Saudi Arabia was \$26,260 [3] (log of percentage relative to US GNI per capita in 1963 is 1.71), close to the level of South Korea. ${ }^{1}$

Table 1 compares three countries that have overcome the middle-income trap to become innovation-based economies with four countries that remain in the trap, but exhibit important signs of progress. The latter also includes the efficiencybased economies of China and Indonesia. For the sampled countries, Table 1 provides the values of gross domestic expenditure on research and development (GERD) and educational investment, both given as percentages over the values of gross domestic product (GDP).

For the innovation-based economies in Table 1, the average value of GERD over GDP is $3.2 \%$. For South Korea, Japan, and Taiwan the values are 3.4, 3.3 , and $2.9 \%$, respectively. The average value for educational investment as a

\footnotetext{
${ }^{1}$ Saudi Arabia is not included in Fig. 1 due to lack of data for 1963 in the World Bank dataset.
} 
Table 1 Comparison of countries based on GERD and educational investment over GDP (2012) [7-12]

\begin{tabular}{l|l|l}
\hline Innovation-based economies \\
\hline Countries & GERD/GDP (\%) & $\begin{array}{l}\text { Educational } \\
\text { investment/GDP (\%) }\end{array}$ \\
\hline South Korea & 3.4 & 7.6 \\
\hline Japan & 3.3 & 4.9 \\
\hline Taiwan & 2.9 & 5.8 \\
\hline In
\end{tabular}

In transition to innovation-based economies

\begin{tabular}{l|l|l}
\hline Mexico & 0.4 & 3.5 \\
\hline Turkey & 0.9 & 3.2 \\
\hline
\end{tabular}

Efficiency-based economies

\begin{tabular}{l|l|l}
\hline China & 1.7 & 3.3 \\
\hline Indonesia & 0.7 & 3.3 \\
\hline
\end{tabular}

percentage of GDP is $6.1 \%$. For example, South Korea invests in education at $7.6 \%$ of its GDP, whereas Taiwan and Japan invest at 5.8 and $4.9 \%$, respectively. Certainly, GERD and educational investments over GDP are relatively high in these countries.

For those countries that are in the middle-income trap, the values of GERD and educational investment over GDP are comparably lower. The average values for Mexico and Turkey that are in the middle-income trap, but in the process of transition to innovation-based economies, are $0.7 \%$ for GERD and $3.4 \%$ for educational investments, both over GDP. The GERD of Mexico stands at $0.4 \%$ of GDP while investment in education is relatively higher at $3.5 \%$ of GDP. The GERD of Turkey is higher at $0.9 \%$ of GDP and the investment in education is $3.2 \%$ of GDP. The average values for China and Indonesia, which are in the middle-income trap as efficiency-based economies, are $1.2 \%$ for GERD and $3.3 \%$ for investment in education, both over GDP. Indonesia invests the same share in educational investments as China but spends less on R\&D as a share of GDP. In contrast, while the value of GERD over GDP is only $0.7 \%$ in Indonesia, it is $1.7 \%$ in China. Even within the middle-income trap, GERD and educational investments over GDP vary for countries that are in a state of transition to innovation-based economies and efficiency-based economies.

\subsection{The Key Role of $R \& D$, Innovation, and Education}

Clearly, the ability of countries to realize an 'exit strategy' to escape the middleincome trap requires an intense effort marked by high levels of investment in GERD and education as shares of GDP. At the same time, these key investments must be matched by an efficient innovation system to transform these inputs into high value-added outputs. This two-pronged approach defines the paradigm shift that countries must implement in order to provide the necessary groundwork for the opportunity to escape from the middle-income trap and become 
innovation-based economies. While there is no single method for countries to execute such a paradigm shift, countries have to develop strategies to increase outputs of knowledge-intensive technologies and high value-added products. This, in turn, depends on the ability to establish the necessary "ecosystem" between actors to trigger R\&D, innovation, and entrepreneurship activities as a launch pad to excel in innovation.

A diverse array of tools and mechanisms are implemented by various countries to promote a flourishing ecosystem for the innovation actors. These mechanisms are discussed from the perspective of international comparison in Sect. 3, based on best practices in emerging, fast-growing, and developed countries. For the purposes of this chapter, these best practices are grouped into four main headings that define ways and means to stimulate and sustain the R\&D, innovation, and the entrepreneurship ecosystem. The first two headings are best practices to foster entrepreneurship, including techno-entrepreneurship and venture capital, and best practices in mission-oriented programs and mega projects. The subsequent two headings involve best practices for the stimulation of research quality and best practices for supporting the innovation system through raising awareness and fostering a culture in $R \& D$, innovation, and entrepreneurship among the related actors. In analogy, these best practices provide some of the "keys" that countries can use to "unlock" a path to exit the middle-income trap. For ease of reference, the key concepts can be identified as entrepreneurship, prioritization, fostering research quality and quantity, and raising awareness of R\&D culture.

Some of these best practices may be equally valid for countries that appear to be high-income economies. Some countries have attained this level based on the abundance of their natural resources. Other countries have combined assets from both their stocks of human and natural capital in creating new value-added products and technologies. These best practices will allow innovation systems to rely, not only on abundances in natural resources, but also on wealth in human capital. KSA for example, as a high-income economy, invests only $0.07 \%$ of GDP as GERD [4]. For oil-rich countries such as KSA and other similar countries, this implies that further investment in GERD and education can better mobilize their potential to ameliorate human welfare. For this reason, in a highly competitive world, even those countries that have reached the status of high-income economies need to pursue excellence in innovation to maintain their performance and allow their innovation systems to flourish and excel to the next level.

\section{Best Practices to Be an Innovation and Knowledge Economy}

For a well-functioning innovation system, it is crucial to strengthen each component of the "ecosystem" in a systems approach. The business sector and entrepreneurs should be at the core of this ecosystem and interact robustly with all other actors. Research activities without business sector linkages will not yield 
the desired results, especially for the aim of escaping the middle-income trap. Therefore, it is mandatory to develop the correct set of support tools and mechanisms to manage a 'complex ecosystem', while strengthening even the weakest component. These mechanisms should also provide a particular emphasis to the process of commercialization. From the perspective of policy-making and policy design, this approach requires a strategic combination of both qualitative and quantitative policy tools.

\subsection{Best Practices to Foster Entrepreneurship}

One of the vital aspects of improving the efficiency of the R\&D and innovation ecosystem is promoting entrepreneurship based on technological and innovation-driven research. Recently, many countries have realized that the main challenge for the innovation system is not the lack of knowledge or technology, but often the inability to drive these innovations to the market. This realization has resulted in a shift of focus in direct $R \& D$ funding among OECD countries. Most OECD countries have now channeled their funding opportunities across the entire R\&D and innovation value chain, including the integrated processes leading to commercialization.

Direct support to aid commercialization includes support to encourage collaboration and knowledge transfer among or between firms and scientific institutions. It further includes direct support to foster the growth of high technology start-up firms, stimulate venture capital activity, and accelerate innovation activity relevant to societal challenges. Such forms of direct support allow governments to target specific barriers that persistently affect innovation performance. For entrepreneurship, these barriers may include the lack of co-operation, barriers for small businesses and individual entrepreneurs to commercialize, or high risk in areas that also have high social returns [13]. In this context, best practices to foster entrepreneurship are examined under the topics of techno-entrepreneurship, venture capital, and entrepreneurship culture. These best practices can further improve the ease of doing business within the ecosystem [14].

\subsubsection{Techno-Entrepreneurship}

The value of an innovative idea increases with commercialization potential. It further increases with the presence of a skilled and qualified techno-entrepreneur capable of taking the idea to the market. For this reason, countries have designed and implemented support mechanisms and programs to encourage techno-entrepreneurship endeavors. Programs that encourage small domestic businesses and/ or individuals to engage in $\mathrm{R} \& \mathrm{D}$ and innovation activities with commercialization 
potential include the SBIR Program (USA), the Individual Entrepreneurship Multi-Phased Support and Co-Financing Programs (Turkey), and the PRISM Program (India).

The Small Business Innovative Research (SBIR) Program, coordinated by the US Small Business Administration, is one of the most well-known schemes. The program enables small businesses to explore their ideas' technological potential and provides an incentive to profit from their commercialization potential. Eleven federal agencies that have a total extramural R\&D budget in excess of $\$ 100$ million allocate a certain percentage of their budget to the SBIR Program. Approximately $\$ 2.5$ billion is awarded through this program annually [15]. The program has three phases with monetary contracts and/or grants awarded in Phases I and II [16]. At the end of the third phase, small businesses are expected to meet specific R\&D government needs and commercialize their ideas.

- Phase I (start-up phase) supports the exploration of the technical merit or feasibility of an idea or technology and awards up to $\$ 150,000$ for approximately six months.

- Phase II provides grants to facilitate the expansion of the results that are obtained from the start-up phase. Up to \$1 million for two years is awarded to Phase II grant holders, who will perform R\&D work and evaluate the commercialization potential of their idea.

- Phase III is designed to accommodate the time for an innovation to move from the laboratory into the marketplace. Small businesses must find private sector funding or non-SBIR federal agency funding. No SBIR funds are awarded in this phase.

The National Science Foundation's (NSF) implementation of the SBIR Program provides direct linkages between SBIR and some of the other support programs. As one of the schemes, I-Corps provides private sector co-financing and mentorship. Similarly, the National Institutes of Health (NIH) presents the Commercialization Assistance Program (CAP) as a supplementary tool to the SBIR program. CAP aims to provide small businesses in the health sector with business mentorship to raise the commercialization potential of the outputs of SBIR projects.

In Turkey, entrepreneurs are supported for their activities across the entire spectrum from the idea creation to the commercialization stage in an integrated manner. The Individual Entrepreneurship Multi-Phased Support Program (TÜBİTAK 1512) [17] aims to support individuals or technology-based start-up firms with ideas that hold promise for transformation into innovative products and services for the domestic or international markets. The program, which is designed and implemented by the Scientific and Technological Research Council of Turkey (TÜBITAK), targets various stages of maturity in R\&D-based entrepreneurship activities. The program, which has a total of four phases, integrates grant-based financial support with mentorship support opportunities. Entrepreneurs, including academics not familiar with business matters, are given opportunities to receive 
training on technical, commercial, and executive issues, as well as mentorship from industrially experienced mentors.

- Phase 1: The program starts with the presentation of a business idea by the entrepreneur to TÜBITTAK. Upon a positive evaluation, the entrepreneur is provided the option of obtaining entrepreneurship training. Phase 1 corresponds to the stage of idea creation and ends with the detailed preparation of the business plan and training.

- Phase 2: Upon further successful evaluation, the entrepreneur receives grant support to realize the business plan and establish the start-up. The start-up is supported with about $\$ 50,000$ of seed capital with the aim of having a technological validation of the proposed idea within 12 months. The activities that may be undertaken at this phase include conceptual design, technical and economic feasibility studies, and technological affirmation (pre-prototype, demonstration, simulation, code algorithm, etc.). The entrepreneur also has the option to request mentorship support. Those firms that demonstrate commercial potential in their outputs may directly skip to Phase 4.

- Phase 3: This phase provides grant support to conduct any additional R\&D studies that may be needed to further develop the commercialization potential of the outputs of the previous phase. To receive funding for this phase, the entrepreneur must submit a project application, now as an established firm, to the SME R\&D Grant Program (TÜBİTAK 1507). In this phase, $75 \%$ of eligible project expenses up to $\$ 250,000$ are grant support entitled. These activities may include detailed design, development of a commercial prototype, experiments, and field tests. Projects that pass the technological affirmation phase are evaluated using special criteria. For those projects that complete this phase successfully, firms may receive approval to pass to Phase 4, upon the preparation of a robust commercialization business plan.

- Phase 4: This phase corresponds to the process of facilitating the entrepreneur's access to finance. Upon the request of the firm, TÜBITTAK sends letters to risk capital firms inviting them to be a partner to the project output. In addition, TÜBİTAK organizes project brokerage events to facilitate the commercialization process of the products.

In the two years since the program's inception, a total of 239 R\&D start-ups have been successfully created, the majority of which have commercialized their research outputs.

In addition to TÜBITTAK 1512, an additional version of the program was established as the Individual Entrepreneurship Multi-Phased Co-Financing Program (TÜBITAK 1512/B) with the purpose of facilitating the access of start-ups to equity financing. In this version, large firms are invited to partner with TÜBITTAK to support start-ups by providing incubation, co-financing, mentorship, and the potential of being the first customer of their products. The program increases the entrepreneur's chances of survival in the market. As a means to complement the TÜBITAK 1512 Program, this version enables entrepreneurs to take advantage of the experience of the private sector and their provision of seed capital 
support, office or rent support for a year, technical expert personnel, and business development [17].

In the Indian context, Promoting Innovations in Individuals, Start-Ups and MSME's Program (PRISM), is implemented by the Department of Scientific and Industrial Research (DSIR) of India and applies a multi-staged approach to supporting entrepreneurs. Any individual with an idea can be supported to transform the idea into a commercially viable product or process. In the proof-of-concept stage, up to $\$ 35,000$ or $90 \%$ of the eligible project costs are supported. In the following stage, which may include real site tests and demonstration, an additional $\$ 350,000$ or $90 \%$ of the eligible project costs can be supported. The duration of the projects can vary between six months and three years, depending on the scope of the idea. As the name of the program suggests, PRISM seeks to 'open up' the full commercialization potential of the idea [18].

\subsubsection{Venture Capital}

Since R\&D investments yield their returns in the medium or even long term, rather than the short term, finding financial support can be a cause of concern for startups. This concern has recently triggered developments in designing programs to support or establish venture capital funds. For example, in China different financing opportunities aim to support the quantity and effectiveness of venture capital firms. A government-based funding agency that is related to the Ministry of Science and Technology (MOST), namely the Torch Center, operates the Techbased SMEs Venture Capital Introductory Fund [19]. The Torch Center provides funds to venture capital firms to subsidize SMEs with seed capital in the approach of supporting the 'fund of funds.' In this scheme, Torch Center encourages and motivates venture capital firms to make equity investments in, and provide investment subsidies to, technology-based SMEs.

Another similar structure is the Start-up Enterprise Development Scheme (SEEDS), run by the government agency that supports Singapore's SMEs, namely SPRING Singapore [20]. The SEEDS Program provides additional capital opportunities for Singapore-based start-up firms that are less than 5 years old. The selection of the start-ups is based on the criteria of the products' innovativeness and/ or processes within the domain of the intellectual property of the start-up. These products and/or processes are expected to have strong growth potential across international markets as well as to be in receipt of initial investment by external investors. It is an equity-based co-financing option that enables SPRING to acquire ownership in the company proportional to its investment up to the maximum rate of $20 \%$ and an exit strategy of five years. Based on SEEDS, SPRING acquires the opportunity to be involved in managerial level decisions and to leverage start-ups that have sufficient capability to proceed to the market.

SPRING provides another investment opportunity for start-ups, namely the Business Angel Scheme, which involves a different scheme. In this scheme, the start-up firm is funded by the registered Business Angels in SPRING's portfolio 
as opposed to any other external investor. If the start-up is able to obtain investment interest and commitment from any of the Business Angel investors, SPRING has the capacity to potentially match the intended amount (dollar-for-dollar) up to a maximum of $\$ 1.5$ million [20]. In addition, like SEEDS, the Business Angel Scheme can acquire equity stakes in the company proportionate to its investments. An advantage of both schemes is that these programs involve experience sharing from SPRING to the start-up. They also provide opportunities for start-ups to benefit from SPRING's investor network.

Another emerging country, Mexico, provides venture capital funds to start-ups as a means to stimulate the entrepreneurial spirit of innovative Mexican firms. The Mexican Ministry of Economy (SE) [21] provides a seed capital co-investment fund for innovative companies, namely the Co-investment Fund Seed Capital. This fund aims to increase the accessibility of seed capital for entrepreneurs and/ or companies and seeks to promote the entrepreneurship ecosystem. The funds go directly into the assets of the fund and/or the project in exchange for equity shares in the newly established firms (up to one-year-old firms). Due to the nature of involving equity shares, the ministry invests up to $50 \%$ in the firm. This threshold is based on the concern of not capturing any control of the start-up. The ministry is careful to contribute with equity shares in the innovative firms to promote firms which have market potential. In addition, SE operates a 'fund of funds' initiative that invests in venture capital funds. The Mexico Venture Program targets domestic and foreign funds that aim to trigger innovative activities in the country. With the Venture Program, Mexico enhances the awareness of venture capital investment opportunities throughout the country by sharing risk with the other investors.

Another example from Turkey is the Venture Capital Funding Program (TÜBİTAK 1514). This program was launched to contribute to the creation of a venture capital ecosystem. The program encourages the establishment of new funds that provide venture capital to innovative SMEs by providing grants to fund managers [17]. This ensures the sustainability of the venture capital ecosystem and enhances the financial support that is specific to the maturity level of the venture capital firms. Accordingly, TÜBİTAK can provide grants to domestic and foreign venture capital funds up to $20 \%$ of the size of the fund. The fund is expected to focus on the early stages (seed and start-up) of equity investments and innovative SMEs that have the potential to develop innovative products, services, and/or production processes and domestic technology. The total size of the venture capital funds that received support from TÜBITAK and are available to invest in start-ups in Turkey has risen to about 700 million USD. Of this amount, about 470 million USD has been raised from foreign venture capital funds [22].

\subsubsection{Entrepreneurship Culture}

In the process of promoting entrepreneurship, programs that support entrepreneurial activities are a commendable start but are only one of the series of steps required to establish a sufficiently fostering environment. For this reason, 
developing 'entrepreneurial culture' is as important as launching programs to enable entrepreneurs to enter the innovation arena. At the same time, the Knowledge Triangle [23] emphasizes the key role of linkages among education, research, and innovation actors in order to utilize education and research for innovation. Fostering innovative capacity and entrepreneurship in universities has thus recently been an important policy tool.

The Singapore Government establishes a council in every university to promote the environment of innovativeness and entrepreneurship. Moreover, specific support mechanisms are used in the system to encourage such activities in universities. The University Innovation Fund provides support for various ranges of activities to generate a climate of innovation in universities, such as entrepreneurship trainings, awards, consultancy service procurement from professors with private sector experience, and internships.

As a ranking index including entrepreneurship, the Entrepreneurial and Innovative University Index was prepared for the first time in Turkey in 2012. Now in its fourth year, the 50 most entrepreneurial and innovative universities are announced annually. Through ranking universities according to their entrepreneurial and innovative performances, the index increases positive competition among universities, hence fostering an entrepreneurial and innovative ecosystem. The universities are ranked according to data collection across a set of 23 indicators in five pillars. These pillars are scientific and technological research competence, intellectual property pool, cooperation and interaction, entrepreneurship and innovativeness culture, and last but not least, economic contribution and commercialization [24].

From a system's perspective, the index is part of a larger strategy to develop a culture and entrepreneurship capability in universities. While the index measures performance, the Capacity Building for Innovation and Entrepreneurship Support Program (TÜBİTAK 1601) supports universities, NGOs, and firms to provide mechanisms for activities including mentorship, training, brokerage events, investor readiness programs, and fundraising events. Under this program, the first call was launched as the University Certification Program for Entrepreneurship (1601.1) that supported undergraduate and graduate entrepreneurship certification programs. In this call, universities are supported in implementing certification programs of a minimum of $120 \mathrm{~h}$ aimed at undergraduate and graduate students as well as academic staff for building entrepreneurship capabilities. Following the training program, certificates are granted to the successful entrepreneurs who pass the evaluation examination [17].

\subsection{Best Practices for Mission-Oriented Programs and Mega Projects}

Even the most successful countries with the most active researchers and facilities may fall short of realizing the potential of their research base. In this situation, it becomes vital to concentrate the dispersed research efforts in a country 
around mission-oriented programs. Such an approach combines the bottom-up demand coming from the research base with top-down policies, to focus the country's research effort to increase the impact of research activities. At the international level, there is an increasing trend toward designing policies that combine top-down and bottom-up approaches based on targeted policies. Policymakers, together with relevant stakeholders, tend to analyze the local dynamics as well as global technological developments in pursuit of determining the areas that are to be supported.

The rationale for these policies is generally linked to the need to stimulate innovation in areas where societal needs are pressing (e.g., energy, health, and environment) and/or where government action can complement market mechanisms with minimal financial outlays. To be efficient, such policies must target specific market or systemic failures and their objectives [13]. The priorities may be selected in areas of relative competitive advantage or in areas that need to be developed in the country to address present or future needs. In mission-oriented approaches, programs in areas of priority and large-scale "mega projects" help to accelerate the emergence of technologies for which there is an urgent and time-bound societal need.

\subsubsection{Mission-Oriented Programs}

As an example from fast-growing BRICS economies, the innovation system of China is known for its mission-oriented approaches for supporting specific R\&D and innovation projects in priority areas. China has systematically used the support instrument, namely the National High-Tech R\&D Program (863), to develop cutting-edge technologies that are identified in the "National Medium and LongTerm Program for Science and Technology Development of China." This program is intended to stimulate the development of advanced technologies in a wide range of fields, for the purpose of allowing China to increase its technological capability and to be more independent of the financial burdens of importing foreign technologies [25].

The 863 Program focuses on developing a number of key technologies in the next five to ten years and establishing technological systems of significant value for societal applications. It aims to accelerate the socio-economic development of the country and enable China to approach or catch up with international pioneers in select fields [26]. Projects are implemented and monitored by a related ministry in the sector, with project budgets differing from one subject to another. One project that has received considerable attention in China and throughout the world is the 863 Key Technology and System Integration Project for Electric Vehicles. Nearly $42 \%$ of the total budget is allocated for critical battery components and electric vehicle integration.

In Turkey, following the adoption of the National Science, Technology, and Innovation Strategy 2011-2016, there has been a paradigm shift toward mission-oriented approaches. Traditionally, project funds had solely been granted 
to researchers through a bottom-up approach where the researcher decided the area/topic on which to work as curiosity-driven research. Based on the strategy [27], nine priority areas were evaluated and adopted by the Supreme Council for Science and Technology (SCST), namely automotive, machinery-manufacturing, information and communication technologies (ICT), energy, water, food, health, space, and defense. Following the adoption of the priority areas, high-level prioritization group meetings prioritized sub-fields of the nine areas. This effectively combined top-down direction setting through the SCST with the bottom-up direction setting of the innovation actors. In yet another level of stakeholder evaluations, TÜBITAK coordinated multi-staged processes based on the use of technology foresight methods, including Delphi surveys, to determine the prioritized topics under the sub-fields. The results of these processes are used in policy design, technology roadmaps, and preparation of project calls. With the wide participation of different stakeholders, Turkey has now completed 10 technology roadmaps and launched over 150 technology roadmap-based calls.

Defining priority areas inevitably calls for revisions and elasticity in support mechanisms. Thematic and call-based programs are most useful when they are adaptable to changing needs. In 2013, TÜBİTAK developed two new call-based, mission-oriented support measures to improve R\&D performance in priority research areas. The Support Program for Research, Technological Development and Innovation Projects in Priority Areas (TÜBİTAK 1511) [28] targets private sector companies. The Support Program for Research, Technological Development and Innovation Projects in Priority Areas (TÜBITAK 1003) [29] is directed toward researchers from both academia and private/public research institutes. While the target audience that will lead the project is different, both programs incentivize the collaboration of private industry and academia/research institutes. Under the aegis of these programs, TÜBİTAK announces calls for project proposals addressing Turkey's priority areas. Applicants submit project applications in response to the calls. Each call is designed to cover specific research areas with the potential of strengthening areas in which Turkey may have a comparative advantage or a demand to accelerate the closing of technological gaps.

The calls of the TÜBITAK 1511 and 1003 coded support programs are determined using thorough analysis of technology roadmaps' outputs, high-level prioritization groups, and private sector problems capable of being solved by means of R\&D activities. Detailed analysis of foreign trade data was also integrated into the process of determining call topics. Presently, these programs satisfy the need of the ecosystem to support product and technology-oriented projects that preferably involve university-industry cooperation. These programs provide a larger budget per project in comparison to curiosity-driven programs so as to encourage R\&D activities to be conducted in prioritized topics. In addition, there are budgetrelated incentives for university-industry cooperation. The number of applications also indicates that researchers are interested in the call-based, mission-oriented approach. The number of applications to both programs has been in excess of 3700 applications. 


\subsubsection{Large-Scale Mega Projects}

In China, 16 National Mega Projects have been launched under the Development Plan (2006-2020). While three are classified as confidential, 13 are characterized as civil-purposed projects and military-purposed projects as listed below [30]. For example, the 'Mega New Drug Development Program', under the aegis of the National Mega Projects Initiative, received about $\$ 2$ billion to be used in the years from 2011 to 2015.

\section{Civil-purposed projects}

1. Core electronic devices, high-end general chips, and fundamental software

2. Mega-scale integrated circuit manufacturing technologies

3. Next generation of broadband wireless mobile networks

4. Advanced digital control machines and fundamental manufacturing equipment

5. Wastewater control and treatment

6. Key new drug innovation

7. Prevention and treatment of key infectious diseases (e.g., HIV/AIDS, hepatitis)

8. Large-scale development of oil \& gas fields and coal-bed gas

9. Breeding of new variety for transgenic biology

\section{Military-Purposed Projects}

1. Large-scale advanced pressurized water reactor and high temperature gas-cooled nuclear power plants

2. Mega-airplanes

3. High-resolution earth observation system

4. Manned space flight and lunar exploration

Similarly, the Korean Government is securing new growth engines for a sustainable economy and improving the quality of life by developing fundamental technology in biology, nano-science, energy, environment, and other promising fields. There are six thematic umbrella support programs being implemented by the National Research Foundation of Korea [31]. The themes are identified and several full-scale projects have been supported under each umbrella program. The mission-oriented, thematic programs are as follows:

1. Bio-Medical Technology Development Program

2. Nano-Material Technology Development Program

3. Next-Generation Information Computing Program

4. High Technology Convergence Technology Development Program

5. Public Welfare \& Security R\&D Program

6. Global Frontier Program

For example, the "Development of New Medicine" is one of the themes that are adopted under the aegis of the Bio-Medical Technology Development Program. This theme's target is to develop 10 commercial therapeutic drugs by the year 
2019. Another initiative for the health sector is The Korea Drug Development Fund. The Ministry of Knowledge Economy (MKE), the Ministry of Health, and the Ministry of Education, Science and Engineering have created this fund for drug development, which has received a total of 27 million USD in contributions.

In addition, mega projects, which are seen to be flagship "landmark" projects, are launched as a special kind of mission-oriented approach in Turkey. Most notably, this includes electric vehicle technology, through the Public Institutions Research and Development Projects Support Program (TÜBİTAK 1007) [32]. The aim of TÜBİTAK 1007 is to solve technological problems and satisfy public institutions' needs by means of R\&D projects. Through the use of TÜBITAK 1007, it has been possible to launch large-scale, high budget mega projects targeting the country's needs. Examples of such projects are the high-resolution communication satellite project, the electric vehicle project, and the wind turbine project. Most of these mission-oriented projects involve large-scale budgets of over 30 million USD.

\subsection{Best Practices for Research Quality Based Stimulation}

Programs to increase the quality of R\&D and innovation outputs are as necessary as new programs to support $R \& D$, innovation, and entrepreneurship. Since R\&D and innovation are one of the main drivers of countries' future growth, prosperity, and wellbeing, it is important to ensure that money is invested in projects with the greatest potential to return effective and quality research outputs [33]. Since universities are one of the main pillars of the innovation ecosystem, increasing the quality of research outputs in the university research environment has been receiving much attention as a policy focus. One of the policy tools that have been introduced are performance-based research funding systems [34]. Overall, best practices to stimulate the quality of research outputs in the innovation system can be classified under the topics of performance-based funding schemes for universities, schemes to increase publication quality in researchers, and performancebased schemes for fast-growing, innovative firms.

\subsubsection{Performance-Based Funding Schemes for Universities}

One of the oldest performance-based research funding systems is the Research Assessment Exercise (RAE) in the UK [35]. Since its launch in 1986, many countries have followed suit and introduced performance-based research funding schemes. Such widespread adoption of performance-based funding schemes for universities has also represented shifts in the quality of research outputs, since universities are so central in many innovation systems. According to international best practices, one of the most important tools of performance-based research funding to foster R\&D facilities in universities is project overhead. Numerous countries 
exert project overhead. Recently, however, a fixed project overhead rate has been widely deemed to be less effective than varying project overhead rate based on performance. This change in methodology allows a boost in R\&D in universities since it fosters increased competition.

Countries that implement varying project overhead rate include the US, the UK, Sweden, and Ireland. The efficiency factor implementation in the UK is one of the leading examples. This practice, initiated in 2011, allows Research Councils UK (RCUK) to evaluate the funded money based on performance. This reduces amounts allocated, if needed, when there are decreases in performance [33]. In this methodology, every university determines a project overhead rate and applies to RCUK annually. At a later date, RCUK uses the method of defining efficiency groups that provides the research organization with the autonomy to make minimal impact savings. This aids in removing uncertainty and does not require the research organization to collect huge amounts of data or RCUK to build expensive monitoring systems.

In the UK, research organizations are categorized into five efficiency groups A to E. The efficiency group A represents the most efficient and E the least efficient. The association with an efficiency group is based on a research organization's absolute indirect cost rates and the relative change in the rate compared with the previous year. Higher Education Institutes (HEIs) in the least efficient group would be subject to increased scrutiny and pressure to reduce their indirect cost rates. The assignment of research organizations to efficiency groups is also subject to annual review. Furthermore, it is important that in the revised methodology to calculate the current rate, the previous year's rate is duly taken into consideration. This allows accounting for the growth rate as the percentage change for higher performing universities.

Some countries continue to exert fixed project overhead rate for universities. At the same time, the possibility of changing to the varying project overhead rate methodology is becoming increasingly up for debate. In Finland, the fixed rate is exerted, namely $46 \%$ for TEKES and $12.5 \%$ for the Academy of Finland. In Ireland, this rate is up to $35 \%$ and there are aims in place for increasing it further [36]. An average of $52 \%$ overhead is used in Sweden, which further plans to implement UK's efficiency factor model in the coming few years. Within the context of the EU Framework Programs, different models are applied with $20 \%$ fixed rate and $60 \%$, conditionally.

Since 2004, a fixed overhead rate at $10 \%$ has been exerted in Turkey for every project. In the new implementation of project overhead, the aim is to raise the rate of $R \& D$ funds in university budgets to $25 \%$ from its current rate of $2 \%$. Therefore, the practice of fixed project overhead rate has been changed and increased from 10 to $50 \%$ based on universities' performance that will be assessed annually based on objective criteria. According to new practice, the project overhead will vary from university to university depending on their performance. A higher level of performance will lead to a higher project overhead for universities. This also means an additional R\&D budget for universities that compete to raise their level of performance. 
Another example of a performance-based funding scheme for universities is awarding successful R\&D outputs, such as publications and patents, and providing incentives based on their success. Recently, such revisions have been implemented in the Czech Republic [37]. The Czech Republic aims to motivate HEIs to increase the quality and the number of students as well as to affect the universities' annually allocated budgets. The revision includes all categories of the R\&D outputs that are measured by awarding them with a certain defined amount. System indicators include several types of publications, e.g., Jimp — article in an impacted periodical, Jneimp - a critical article in an international database such as SCOPUS or ERIH, patents and other results of applied research. The proportion of points that are gained by various categories of research institutions varies according to levels of success in these categories.

\subsubsection{Performance-Based Funding Schemes for Researchers}

With the new Project Performance Award in Turkey, successfully completed projects are awarded to increase the effects of funded projects based on performance. For performance assessment, a total of 36 sub-criteria are taken into consideration. These include the number of indexed articles in A, B, and C class journals, the number of other refereed articles, and the number of citations according to nine main criteria [38]. The nine main criteria include articles, scientific papers, books, awards, patents, products/models/firms, dissemination, researcher trainings, and new projects. The points that are gained with respect to these criteria and the successfully completed projects are awarded with up to $\$ 48,000$ in addition to the project grant, incentive premium, and project overhead. In practice, this incentive bonus may pass to the researchers as an additional $\$ 1500$ in monthly income.

Another example of performance-based funding for researchers is the Incentive Program for International Scientific Publications (UBYT), which has been initiated in Turkey to boost the quality of scientific publications. The program has been revised to increase the rate of international citations per publication, which is a quality indicator. According to the program, journals that are included in international citation indexes are evaluated using objective parameters, such as the impact factor and citation half-life. In this respect, publications are compared to their counterparts in their research areas and every publication receives a certain mark. Higher incentives are granted for better quality [38].

\subsubsection{Performance-Based Funding Schemes for Firms}

In China, the Beijing Zhongguancun Sci-Tech Financing Guaranty Co. Ltd., which is a company in the Zhongguancun Park [39], known as the "Silicon Valley of China," identifies its fast-growing 'gazelle' firms and provides performance-based incentives. Based on the Gazelle Plan, the above-mentioned company determines the 3000 most innovative gazelle firms annually and facilitates banks to provide 
low-interest loans in a credit guarantee system. The expected incomes of the firms are between 1.5 million and 80 million USD and are expected to show an increase of approximately 10-20\% over the previous year's levels. According to other performance criteria, such as the number of patents and innovation activities, the firms are identified based on a ranking of up to five stars. According to the number of stars, the percentage of the project budget for which a low credit loan can be obtained by the firm from the bank is varied. For example, a five star ranking firm can receive a low credit loan for $40 \%$ of the project's budget, while a firm with one star ranking can receive a loan for only $20 \%$ of the project's budget.

\subsection{Best Practices for Supporting the Innovation System with $R \& D$ Awareness}

For any policymaker, it is crucial to sustain an ecosystem that not only utilizes the performance of the current actors to the maximum extent, but also attracts newcomers with promising potential for the system's future. From this aspect, it is vital to raise awareness and diffuse a penetration of R\&D and entrepreneurship culture to support the innovation system. There are several mechanisms that can be identified as embodying best practices in the process of raising awareness of R\&D culture. The two headings under which these best practices are discussed are diffusing $R \& D$ culture in researchers and diffusing $R \& D$ culture in society.

\subsubsection{Diffusing the Penetration of R\&D Culture in Researchers}

An increasing emphasis is placed on providing support to the build-up of technology transfer capacities in countries to enhance technological collaboration between public research institutes, HEIs, and enterprises. As an example, the Mexican Government operates a program called the Program for the Creation and Capacity Building of Knowledge Transfer Offices (KTOs). This program aims to facilitate private sector access to the knowledge produced within universities and research centers and to encourage the fulfillment of academia's 'third mission.' This 'third mission' has been identified as the commercialization of knowledge through technology transfer and academic spin-offs. The government provides vouchers for innovation through KTOs for the purpose of stimulating the demand of companies for innovative solutions produced by knowledge-generating institutions. This program also provides medium-term grants to KTOs for knowledge transfer and linkages with the private sector in an effort to promote KTO growth and development.

Other mechanisms, implemented in almost every middle- and high-income country, are policy tools to support Technology Transfer Offices (TTOs). In Turkey, the TÜBITTAK 1513 Support Program [17] provides grant support for existing and new TTOs. The aim is to trigger universities' innovation and 
entrepreneurship by improving the quality of TTO services for commercializing universities' knowledge and technology. Under TÜBITTAK 1513, five categories of activities are eligible for support. These include awareness building and training/mentorship services, services to assist in applying for R\&D project support, activities to promote university-industry collaboration, and project development/ management. It also includes services to manage intellectual property rights and licensing as well as firm establishment and entrepreneurship services. Through these activities TTOs seek to assist in transforming the technology-based assets of universities into commercial outputs. In addition, TTOs assist in the formation of university-industry collaboration and the production of knowledge and technology according to industry's needs. TTOs will be funded for 10 years under the TÜBITAK 1513 Program. The call is open for the top 50 entrepreneurial and innovative Turkish universities, and each university is eligible to receive up to approximately five million USD.

The South Korean Twinning Program is another example of such a support mechanism. This program encourages information exchange between leading TTOs and newly established or yet to be established TTOs. In this process, all South Korean TTOs are classified as leaders, novices, or newly established. Based on these classifications, leader TTOs are expected to share their experiences with novice and newly established TTOs. The amount of support given to TTOs and its duration can also be shaped by these classifications.

In Brazil, the National Incubator and Technological Park Support Program (PNI), implemented by the Ministry of Science, Technology and Innovation (MCTI), is an integrated program that provides incubators, TTOs, and technology parks with grant support [40]. Supported activities include undertaking benchmarking studies with international case studies of other incubators and TTOs outside Brazil and market analysis service provision to entrepreneurs. At the same time, the CERNE Model allows the country's 384 incubators to be classified according to their maturity levels. At each level, the incubators are expected to fulfill certain activities based on best practices.

Another support program that is initiated to boost the dissemination of R\&D project culture is the R\&D Funding Program for Beginning Researchers (TÜBITAK 3001) [28]. This new program provides opportunities for researchers who have not previously received any funding to apply for their first project and be evaluated in a separate pot from the big players. This provides a means to support researchers at the beginning of their research careers while encouraging them to gain experience. Researchers in universities and public and private organizations who have not previously received support as principal investigators can apply to this new program. The program's advantages are that it has a high support ratio, a fast evaluation process, and there is no limitation for the number of applications. The program offers grants of up to $\$ 25,000$ per project, which includes scholarships, support of trips for scientific activities, support for project dissemination costs, and an incentive premium. The total duration of the R\&D project may be up to 24 months. Since the initiation of this program, $40 \%$ of beginner researchers in Turkey have been induced into actively practicing R\&D culture. 
In Japan, new technological developments are shared within the scope of two programs that provide bi-directional exchanges between universities and industry. In New Technology Presentation Meetings, academics make presentations to industry, while the needs of the industry are shared through presentations by industry to academia within the scope of Open Innovation Seminars. Both of these programs increase knowledge diffusion within the innovation system while increasing awareness of R\&D culture. These programs also support undertakings, including the Strategic Promotion of Innovative Research and Development (S-Innovation) Program, to direct promising seeds from the project results of basic research into key technologies for new industries [41]. Such initiatives allow Japan to create the foundations of future industries and sustain economic growth.

\subsubsection{Diffusing the Penetration of R\&D Culture in Society}

Another important aspect of raising awareness of R\&D culture in society is to foster science, technology, engineering and math (STEM) education starting from early ages. STEM education is an area that receives high focus in many countries. One of the examples is the US, which supports science fairs by many government agencies. Recently, the US has further initiated a Science Fair Program under the auspices of the US President's 'Educate to Innovate' policy. The White House Science Fair featured over 100 students from more than 30 states, representing more than 40 different STEM competitions and organizations that recognize the talents of next-generation scientists, engineers, inventors, and innovators. Approximately 30 student teams had the opportunity to exhibit their projects as part of the fair. The President viewed student work exhibits in person, ranging from breakthrough basic research to new inventions, and delivered remarks to an audience of students, science educators, and business leaders on the importance of STEM education to the country's economic future [42].

Raising public awareness of science can be another area of priority as a means of diffusing the penetration of R\&D culture in society. One of the best practice examples is the European Union Contest for Young Scientists, which is an initiative of the European Commission. Within the Framework Programs for Research and Technological Development, and the European Research Area (ERA), science and societal activities aim to build an increasingly harmonious relationship between scientific endeavors and European society at large. In this context, the contest promotes the ideals of cooperation and interchange between young scientists. Young scientists also have the chance to meet others with similar abilities and interests and to be guided by some of the most prominent European scientists. The EU Contest has been the annual showcase of the best of European student scientific achievement since it was initiated as a Europe-wide student science fair in 1989. It attracts widespread media interest while giving students the opportunity to compete with the best of their contemporaries at the European level. The 25th contest in 2013 brought together 85 projects from 37 countries with 126 promising young scientists aged 14 to 21 . Winners shared $\$ 74,000$ in prize money and other prizes, such as science trips [43]. 
Serving the same objective, the USA Science \& Engineering Festival is another best practice. The mission of the festival is to stimulate and sustain the interest of youth in STEM. In addition to top-level support, festivals include hands-on activities and live performances by science celebrities, explorers, best-selling authors, entrepreneurs, and world-renowned experts.

As another example of large-scale public effort to diffuse science in society, the newly established support program in Turkey aims to create awareness of science and technology issues and to promote scientific culture among young people through science fairs at public schools. Based on the Science Fairs Support Program [44], public schools across the country are given monetary support to hold science fairs for students in Grades 5-12 in cooperation with the Ministry of Education. In the first year of the program, 1092 schools were funded. The fairs were attended by approximately one million visitors and 30,000 projects were exhibited by 64,000 students in consultation with more than 15,000 teachers.

In addition to periodic large-scale events, such as science fairs, other examples are the Science Centers that remain at the service of the public on a continuous basis. In Turkey, the SCST resolved that a science center is to be opened in every Turkish province by the year 2023, starting with the metropolitan municipalities. The Science Centers [44] will be venues for the interactive sharing of scientific knowledge with the public as well as a means of enhancing scientific culture and increasing the rate of scientific literacy in society. In line with these developments, TÜBITAK launched the Science Centers Development Support Program that is initially being used to support exhibits in metropolitan municipalities in a local partnership model.

Following the SCST's decision, contracts have been signed with four metropolitan municipalities. The Konya Science Center has recently been opened with the Prime Minister's participation in an opening ceremony. The other two science centers are expected to be opened in 2016. All centers are located in modern structures with stateof-the-art facilities. For example, the Konya Science Center is 25 thousand square meters including exhibition areas, training sections, conference halls, and libraries. It is constructed over an area of 100 thousand square meters. The Konya Science Center aims to be one of the three best science centers in the world. Currently, 235 exhibitions are designed internationally and 40 are implemented in the newly opened center. One of the forthcoming exhibitions is "Sultans of Science," which includes 50 exhibition units regarding contributions of scientists and inventors to astronomy, math, architecture, and medical sciences that were transferred to Europe as the scientific advances that laid the foundation for the European Renaissance.

\section{Recommendations for Excellence in Innovation to Escape the Middle-Income Trap}

The effort that countries must make to escape the middle-income trap requires an intense dedication to strengthening the $R \& D$, innovation, and entrepreneurship ecosystem to enable the process of attaining the peak of excellence in innovation. The pursuit of perfecting the ecosystem to the best that it can be requires boosting 
the performance of the innovation system and its actors. Ultimately, well-functioning ecosystems can enable entire economies to become knowledge based and innovation driven.

Best practices from emerging and fast-growing economies (including innovation-based economies, transition to innovation-based economies, and efficiencybased economies) have indicated that a series of support mechanisms and sound policy design are needed to effectively foster R\&D, innovation, and entrepreneurship. For ease of comparison, these support mechanisms have been grouped into entrepreneurship-oriented best practices, mission-oriented programs, and mega projects, stimulation of research quality, and supporting the innovation system through R\&D culture and awareness among innovation actors and society. Based on the overview of these best practices, four key recommendations are made:

- Support mechanisms that are designed to have varied, phased characteristics are useful for promoting entrepreneurial activities stage-by-stage. Based on best practices, these phases may address the level of maturity of start-up firm establishment, the preparation and implementation of the business plan, support for proof-of-concept and related $\mathrm{R} \& \mathrm{D}$ activities, and transition to the commercialization phase from idea to the market. At the same time, these support mechanisms should be presented in a robust policy mix that integrates mentorship support and venture capital funds' availability. If necessary, especially in emerging economies, the venture capital funds can be stimulated and encouraged through "fund of funds" approaches. In addition, best practices to promote an increase in the entrepreneurship culture in universities include the design and implementation of a novel university ranking index.

- The implementation of mission-oriented approaches that integrate both top-down direction setting and the bottom-up interests of the researchers is instrumental in allowing the channeling of resources toward the development of critical technologies. These approaches are particularly useful for gaining precious time in the process of catching up to the outputs of more sophisticated innovation systems and innovation-based economies. The flexibility, and thus the success, of mission-oriented approaches can be enhanced with the systematic implementation of call-based programs, which are crucial for increasing innovation excellence. In addition, mega projects that are implemented as special kinds of mission-oriented approaches will aid in directing innovation actors toward large-scale projects.

- Approaches that favor excellence should be able to complement the larger effort of improving the performance of the innovation ecosystem, especially toward producing the innovative outputs that will aid the country in escaping the middle-income trap. Such approaches that favor research excellence and research quality include the variability of project overheads according to research performance, as well as more innovative approaches to increase the level of positive competition between universities. This may further relate to the results of a university ranking index. Overall, tools to improve research quality may involve performance-based incentive schemes for universities, researchers, and firms. The design of policy instruments to improve research quality in the ecosystem will be as important as new programs. 
- The larger effort to escape the middle-income trap by taking as large strides as are possible toward becoming an innovation-based economy requires the intake of new innovation actors into the system. The diversity can range from $R \& D$ actors due to submit their first $R \& D$ project to the encouragement of future entrepreneurs and researchers through science fairs. At the same time, it is important that the level and penetration of science literacy is diffused within society so that the appreciation and usage of technological innovations in society can be increased.

\section{Policy Advice to Improve Innovation Excellence in Saudi Arabia}

More specific recommendations can be made for the policy-making process in Saudi Arabia to strive for innovation excellence based on the combined effect of its natural and human capital. For example, King Abdulaziz University (KAU) has already established an investment arm by Royal Decree known as the 'Wadi Jeddah' Closed Joint Stock Company. As one of Saudi Arabia's first experiments of its kind, the funds are planned to have a business model based on knowledge transfer, R\&D, and profit. For the effective use of the fund, this subsidiary may be mobilized to provide seed capital to start-ups for promoting entrepreneurship in a scheme that is similar to the multi-phased programs as overviewed in this chapter, i.e., SBIR Program, TÜBITAK 1512, and PRISM. Such a fund, or other such funds, may also be transformed into a venture capital fund to support innovative ideas with the potential to create high value-added products. Based on the best practices of the Torch Center, SPRING SEEDS, the Mexico Venture Program, and TÜBITAK 1514, it is envisioned that Saudi Arabia can establish a special scheme to stimulate the country's venture capital environment. In addition, and from another aspect, KAU can establish a certification program to promote university students' entrepreneurial activities. All three of these recommendations need to be planned in concurrence so that they may reinforce the needs of entrepreneurs and the country's entrepreneurship ecosystem.

Regarding a university ranking capable of reflecting the needs of emerging economies, the unique Turkish experience in establishing the 'Entrepreneurial and Innovative University Index' may be taken as a best practice for a similar index that meets Saudi universities' needs. For example, the 'Academic Ranking of World Universities 2014' [45] uses six indicators to rank universities. These indicators include the number of alumni and staff winning Nobel Prizes and Fields Medals, the number of highly cited researchers selected by Thomson Reuters, the number of articles published in the journals "Nature" and "Science", the number of articles indexed in the Science Citation Index-Expanded and Social Sciences Citation Index, and the per capita performance of a university. Among these, Nobel Prizes and Fields Medals may only be applicable to elite universities and may not be highly relevant for emerging economies. These particular indicators are not suited to promote a positive atmosphere of competition in universities to stimulate entrepreneurial activities. Despite the fact that KAU and three other Saudi universities 
are already included in the rankings, it would be advisable that a separate index is established based on the Turkish experience with customized indicators.

The ranking of universities may further be integrated with best practices to stimulate research quality based on ranking performance. For example, those universities that rank higher in the index may receive incentives in performance-based funding schemes similar to those in the UK. A similar scheme may also be implemented for researchers so that higher performing researchers can receive financial awards in addition to the project grant. At the same time, in addition to incentives for mature researchers, activities to foster and complement STEM education in youth can be initiated at an early age, for example by means of science fairs and festivals. Best practices in this respect may be taken from the EU Contest for Young Scientists, the USA Science \& Engineering Festival, and the Science Fairs Support Program in Turkey.

Furthermore, King Abdulaziz City for Science and Technology (KACST) is renowned for launching major projects, such as the Saudisat-4 Satellite and the decoding of the Arabian Camel Genome. The current position of KACST could be used to establish a support program for 'mega projects' that would give direction to major R\&D and innovation activities geared toward the country's priorities and/or the strategy technology sectors of KACST. In the mega projects, the topics could be determined in mission-oriented approaches and the collaboration of leading R\&D actors in the country could be promoted with financial incentives within the project budget. More specifically, the research institutes and strategic technology sectors (i.e., water technology, oil and gas technology, energy technology, petrochemicals, advanced materials, nanotechnology, and building and construction technology) could each have at least one major project that could be dedicated to improving innovation excellence in the country based on the generation of new products and technologies. Best practices may be taken from the National Mega Projects in China, the South Korean initiatives, and the TÜBİTAK 1007 program. In this manner, Saudi Arabia and other countries can take strides in coupling assets of both natural and human capital in the ascent toward furthering "excellence in innovation."

\section{Conclusions}

This chapter has provided empirical evidence and best practices related to the importance of investing in $\mathrm{R} \& \mathrm{D}$, innovation, and education to attain the highest apex of excellence in innovation. In total, 35 international best practices have been provided across the four categories of fostering entrepreneurship, mission oriented programs, research quality based stimulation, and supporting the innovation system with R\&D awareness. Table 2 summarizes the countries of these best practices along with key recommendations. These best practices are equally valid for countries that are in the process of escaping the middle-income trap and for technologically less advanced oil-rich countries that have obtained high income status based on the exploitation of natural resources. Countries with excellence in innovation need to combine assets from the stocks of both human and natural capital to create new value-added products and technologies. 


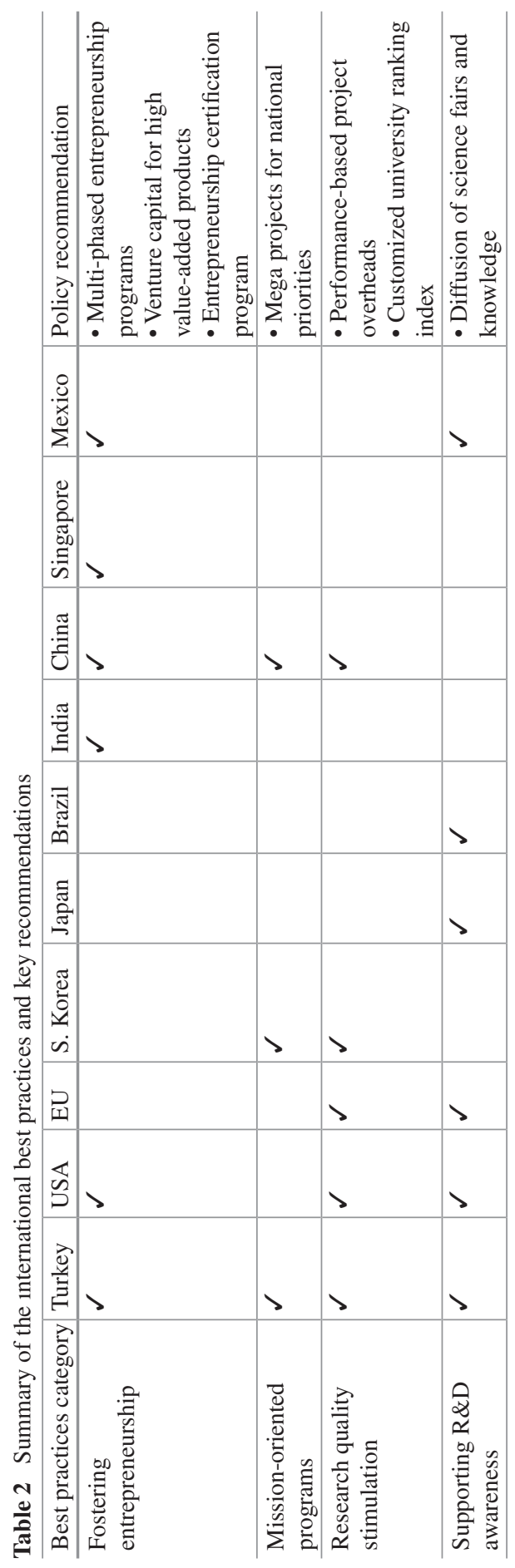


Open Access This chapter is distributed under the terms of the Creative Commons Attribution Noncommercial License, which permits any noncommercial use, distribution, and reproduction in any medium, provided the original author(s) and source are credited.

\section{References}

1. Gill, I., \& Kharas, H. (2007). An east asian renaissance: Ideas for economic growth. Washington D.C.: World Bank.

2. Im, F. G., \& Rosenblatt D. (2013). Middle-income traps, a conceptual and empirical survey. Policy Research Working Paper, World Bank.

3. World Bank Data Set, GNI Per Capita, PPP Current 2011 Dollars, http://data.worldbank.org/

4. World Bank, China 2030. (2012). Building a modern, harmonious, and creative high-income society.

5. OECD. (2013). The People's Republic of China: Avoiding the middle-income trap policies for sustained and inclusive growth (p. 3).

6. World Economic Forum. (2015). The global competitiveness report 2014-2015.

7. OECD. (2014). Education at a glance 2014: OECD indicators (p. 229)

8. World Bank, Education statistics: Education attainment.

9. Ministry of national education statistics 2011-2012 (p. 209).

10. Turkish statistical institute (TurkStat), http://www.turkstat.gov.tr/

11. OECD. (2013). Main science and technology indicators. Paris: 2013.

12. UNESCO institute for statistics, GERD as a percentage of GDP Saudi Arabia, http://www.uis.unesco.org/

13. OECD. (2011). Business innovation policies: Selected country comparisons (p. 15).

14. World Bank. (2013). Doing Business 2014 Understanding Regulations for Small and Medium-Size Enterprises (11th ed.).

15. SBIR program, http://www.acq.osd.mil/osbp/sbir/about/index.shtml

16. SBA, http://www.sba.gov/category/navigation-structure/about-sba

17. The scientific and technological research council of turkey, entrepreneurship programs, http://www.tubitak.gov.tr/tr/destekler/girisimcilik/ulusal-destek-programlari

18. Department of scientific and industrial research, PRISM program, http://www.dsir.gov. in/12plan/prism/prism.htm

19. Torch Center, http://168.160.159.71/english/areas_three.htm. Accessed July 2014

20. SPRING SEEDS, http://www.spring.gov.sg/entrepreneurship/fs/fs/Pages/business-angelscheme.aspx

21. Secretaría de Economía, http://www.economia.gob.mx/en

22. The supreme council for science and technology, presentation of TUBITAK president, http://www.tubitak.gov.tr/tr/icerik-bilim-ve-teknoloji-yuksek-kurulu-28-toplantisi-6-ocak2015

23. European Commission, Knowledge triangle and innovation, European institute of innovation and technology.

24. TÜBİTAK, Entrepreneurial and innovative University index, http://www.tubitak.gov.tr/tr/kur umsal/politikalar/icerik-girisimci-ve-yenilikci-universite-endeksi

25. Wu, H. (2000). The progress of communication technology subject of hi-tech research development plan of China. In International Conference on Communication Technology Proceedings. Beijing.

26. 863 program, http://www.most.gov.cn/eng/programmes1/200610/t20061009_36225.htm

27. TÜBİTAK, http://www.tubitak.gov.tr/tr/kurumsal/politikalar/icerik-ubtys-2011-2016

28. TÜBITTAK, Academic grant programs, http://www.tubitak.gov.tr/tr/destekler/akademik/ulu sal-destek-programlari

29. TÜBI TAK, Industrial grant programs, http://www.tubitak.gov.tr/tr/destekler/sanayi/ulusaldestek-programlari 
30. Chinese Government, National S\&T major projects, www.nmp.gov.cn

31. National Research Foundation of Korea, http://www.nrf.re.kr/nrf_eng_cms/

32. TÜBITAK, Public grant programs, http://www.tubitak.gov.tr/tr/destekler/kamu/ulusal-destekprogramlari

33. Research Councils UK. (2011). Efficiency 2011-15: Ensuring excellence with impact.

34. Hicks, D. (2011). Performance-based University research funding systems. Elsevier Research Policy.

35. Research assessment exercise, http://www.rae.ac.uk/

36. The higher education authority, report of the group on research Overheads, 2003.

37. EC European Universities forum for financial sustainability project, from incremental funding to quality \& performance indicators: Reforms of higher education funding in the Czech Republic, 2012.

38. TÜBITAK, Applications and directives, http://www.tubitak.gov.tr/tr/destekler/akademik/uygu lamalar-ve-yonergeler

39. Zhongguancun Science Park, http://en.zhongguancun.gov.cn/

40. Ministério da Ciência, Tecnologia e Inovação, http://www.mcti.gov.br/

41. Japan science and technology agency, research and development programs focused on technology transfer, http://www.jst.go.jp/EN/operations/operation_b.html

42. White house science fair fact sheet \& backgrounder, 2014, http://www.whitehouse.gov/ the-press-office/2014/05/27/white-house-science-fair-fact-sheet-backgrounder

43. EC EU contest for young scientists, http://ec.europa.eu/research/eucys/

44. TÜBITAK, Science and society grant programs, http://www.tubitak.gov.tr/tr/destekler/bilimve-toplum/ulusal-destek-programlari

45. Academic ranking of world Universities 2014, http://www.shanghairanking.com/WorldUniversity-Rankings-2014 